\title{
Prevalence, characteristics and management of frequently exacerbating asthma patients: an observational study in Sweden (PACEHR)
}

\author{
Christer Janson ${ }^{1}$, Karin Lisspers ${ }^{2}$, Björn Ställberg ${ }^{2}$, Gunnar Johansson², \\ Marcus Thuresson ${ }^{3}$, Gunilla Telg ${ }^{4}$ and Kjell Larsson ${ }^{5}$
}

Affiliations: ${ }^{1}$ Respiratory, Allergy and Sleep Research, Dept of Medical Sciences, Uppsala University, Uppsala, Sweden. ${ }^{2}$ Public Health and Caring Science, Family Medicine and Preventive Medicine, Uppsala University, Uppsala, Sweden. ${ }^{3}$ Statisticon AB, Uppsala, Sweden. ${ }^{4}$ AstraZeneca Nordic-Baltic, Södertälje, Sweden. ${ }^{5}$ The National Institute of Environmental Medicine, Karolinska Institutet, Stockholm, Sweden.

Correspondence: Christer Janson, Respiratory, Allergy and Sleep Research, Dept of Medical Sciences, Uppsala University, Akademiska Sjukhuset, 75185 Uppsala, Sweden. E-mail: christer.jansonamedsci.uu.se

@ERSpublications

Room for improvement exists in identification and management of frequently exacerbating asthma patients in Sweden http://ow.ly/qqN030ktv8T

Cite this article as: Janson C, Lisspers $\mathrm{K}$, Ställberg B, et al. Prevalence, characteristics and management of frequently exacerbating asthma patients: an observational study in Sweden (PACEHR). Eur Respir J 2018; 52: 1701927 [https://doi.org/10.1183/13993003.01927-2017].

ABSTRACT The aim of the study was to investigate the prevalence, management and characteristics of asthma patients with frequent exacerbations.

Data from asthma patients (aged $\geqslant 18$ years) identified in primary care medical records were linked to Swedish national health registries. Exacerbations were defined as hospitalisations, emergency visits and/or collection of oral steroids. Frequent exacerbations were defined as two or more exacerbations per year during the 3-year observation period.

Of 18724 asthma patients, $81.49 \%$ had no exacerbations and $6.3 \%$ had frequent exacerbations in the year prior to the index date. Frequent exacerbations were observed yearly for $1.8 \%$ of the patients. Frequent exacerbators were older, more often females, and had increased eosinophil and neutrophil counts, lower lung function, and more comorbidities than patients without exacerbations. There was a slight increase in asthma medication claims and a slight decrease in physician visits compared with baseline, both in the group with and the group without frequent exacerbations.

Patients with frequent exacerbations were characterised by greater age, female predominance, high eosinophil and neutrophil counts, and high prevalence of comorbidities. This study indicates that the Swedish healthcare system lacks efficiency to adjust treatment and management for this patient group. With new treatment options targeting severe asthma available, identification of these patients should be in focus to ensure reduction of exacerbations.

This article has supplementary material available from erj.ersjournals.com

Received: Sept 222017 | Accepted after revision: June 112018

Copyright $\odot$ ERS 2018. This article is open access and distributed under the terms of the Creative Commons Attribution Non-Commercial Licence 4.0. 


\section{Introduction}

Management of asthma has developed and undergone large changes during the last three decades, with new treatment options available and with established and continually updated international guidelines [1]. Despite this, reports show that asthma still remains uncontrolled in a vast proportion of patients [2-5], has major negative effects on health-related quality of life (HRQoL) [6, 7], and causes a substantial economic burden on healthcare and society $[8,9]$. A large part of the disease burden is caused by asthma exacerbations [10], where frequent exacerbations may lead to a decline in lung function, resulting in more severe airway obstruction and airway remodelling [11].

In patients with chronic obstructive pulmonary disease (COPD), a large observational cohort study has reported an increased susceptibility to exacerbations reflecting a specific COPD patient phenotype [12]. This phenotype was associated with more severe disease and prior exacerbations, and independently also with a history of gastro-oesophageal reflux disease, poorer HRQoL and elevated white blood cell counts [12]. In asthma, a recent cohort study in adults and children with severe asthma found an association between exacerbations and blood eosinophils, bronchodilator responsiveness, body mass index, chronic sinusitis and gastro-oesophageal reflux disease, indicating a distinct exacerbation-prone phenotype also in asthma [13].

The association of high blood eosinophil counts and frequent exacerbations has been previously described [13-15], and eosinophilic inflammation is present in $\sim 50 \%$ of patients with asthma [16]. New anti-interleukin (IL)-5 treatments targeting eosinophils with different modes of actions have been shown to significantly reduce the number of exacerbations and the need for maintenance oral steroid treatment [16-18]. For smokers and ex-smokers, high blood neutrophils have also been associated with frequent exacerbations, indicating that different types of systemic inflammation have an impact on the aetiology of frequent exacerbations in asthma patients [14].

Multimorbidity is common in patients with long-term disorders. A study of a large Scottish primary care database consisting of almost 1.8 million individuals showed that half of the patients with asthma had at least one comorbidity [19]. This study did not include rhinitis among the comorbidities, but it is known that most asthma patients have comorbid upper airways disease [20,21], and there is a strong association between perennial rhinitis and asthma [18]. Furthermore, one-third of elderly asthma patients have features of both asthma and COPD, implying increased disease severity and more frequent exacerbations compared with patients with either disease alone $[22,23]$. In addition, almost half of asthma patients have chronic bronchitis, significantly more in smokers than in never-smokers (50\% versus 40\%, respectively) [24]. Other common comorbidities in asthma patients are stroke and diabetes $[25,26]$.

In Sweden, the majority of asthma and COPD patients are managed in primary care. Research utilising data extracted from electronic medical records from primary care, merged with national registry data, have previously been used to study patient management in COPD [27, 28]. The aim of this study was to investigate the prevalence, management and characteristics of patients with frequent exacerbations in a Swedish primary care asthma population.

\section{Methods}

\section{Study design}

In this observational cohort study, primary care medical records data for asthma patients from 36 primary care centres were extracted using an established software system (Customized eXtraction Program; Pygargus, Stockholm, Sweden) [29] and linked to data from Swedish national health registries, covering mandatory individual health data on a full population level. The unique personal identification numbers were replaced with study identification numbers prior to data processing. Morbidity data were collected from the National Patient Register, inpatient hospital care (admission and discharge dates, and main and secondary diagnoses) and outpatient hospital care (number of contacts and diagnoses as specified by International Classification of Diseases, 10th Revision, Clinical Modification (ICD-10-CM) codes). Data on drug prescriptions were collected from the Swedish Prescribed Drug Register (collection date, drug type, dosage and reason for prescription). The data collection method has been described in detail previously [30]. Data linkage was performed by the Swedish National Board of Health and Welfare; the linked database was managed by the Dept of Medical Sciences, Respiratory Medicine at Uppsala University, Sweden. The study protocol was reviewed and approved by the regional ethics committee in Uppsala, Sweden (approval 2014/446).

\section{Study population}

All patients aged $\geqslant 18$ years with a record of drug collection for obstructive pulmonary diseases (Anatomical Therapeutic Chemical code R03) during 2011-2012 and a prior physician diagnosed asthma (ICD-10 code J45-J46) were eligible for inclusion (index date). All patients were observed during a 3-year period, where the baseline year was the year before the index date, and years 2 and 3 are the years following the index date. Patients with a diagnosis of polymyalgia rheumatica (ICD-10 code M35.3) or 
rheumatoid arthritis (ICD-10 code M05) were not included in order to exclude patients with potential continuous treatment with oral steroids for reasons other than asthma (figure 1). Only oral corticosteroid (OCS) prescriptions intended for asthma exacerbation treatment were included, ascertained by individual and manual clinical verification.

\section{Outcomes and variables}

An exacerbation was defined as an asthma-related inpatient hospitalisation (asthma (J45-J46) as primary diagnosis) and/or asthma-related emergency visit at hospital (J46.9) and/or a collection of OCS in primary or secondary care due to an exacerbation of asthma. Repeated exacerbations occurring within 14 days were calculated as one single event.

Lung function measurements, i.e. forced expiratory volume in $1 \mathrm{~s}$ (FEV1) and forced vital capacity (FVC), were recorded according to the primary care routine and obtained from the medical records [31, 32]. Data on blood eosinophil and neutrophil counts were collected from the medical records. Medications were defined by Anatomical Therapeutic Chemical codes (inhaled corticosteroids (ICSs) (R03BA), long-acting $\beta_{2}$-agonists (LABAs) (R03AC12, 13, 17 and 18, R03CC12), fixed ICS/LABA combination (R03AK), short-acting $\beta_{2}$-agonists (R3AC02 and 03), leukotriene receptor antagonists (LTRAs) (R03DC) and OCSs $(\mathrm{H} 02 \mathrm{AB}))$.

\section{Statistical analyses}

Baseline characteristics were described as mean and standard deviation for continuous variables, and absolute and relative frequencies for categorical variables. Comparisons between the two groups at baseline were performed using ANCOVA for continuous variables and logistic regression for bivariate variables. All analyses (except age and sex) were adjusted for age and sex. Comparisons of within-group changes from baseline to year 2 were performed using exact McNemar tests and comparisons of changes in proportions over time were performed using a generalised estimation equation model, using data for all 3 years, where the p-value for the interaction between group and time is presented. The generalised estimation equation models were adjusted for age and sex.

The consistency of the classification of being a nonuser and a frequent user over time was calculated as the positive predictive value ( $\mathrm{PPV}$; i.e. the likelihood that a frequent user remains a frequent user) and the

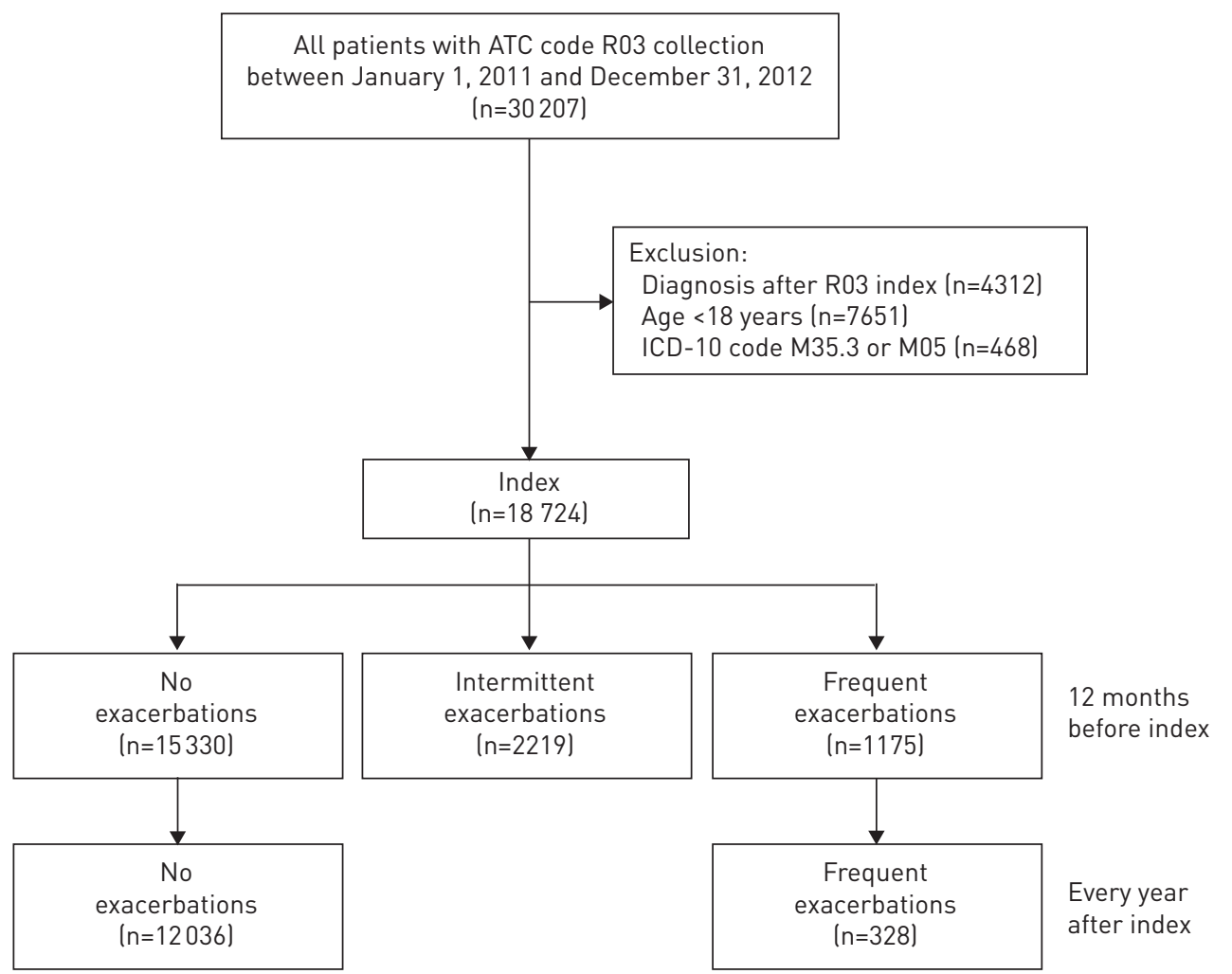

FIGURE 1 Patient flowchart. ATC: Anatomical Therapeutic Chemical; ICD-10: International Classification of Diseases, 10th Revision. 
negative predictive value (NPV; i.e. the likelihood that a nonuser remains a nonuser). Statistical analyses were performed using SAS version 9.3 (SAS, Cary, NC, USA) and R version 3.2.3 (www.r-project.org).

\section{Results}

Exacerbations history at index

The study included 18724 asthma patients, of which 15330 (81.5\%) had no recorded exacerbations, 2219 (11.9\%) had one recorded exacerbation and the remaining 1175 (6.3\%) patients had at least two exacerbations during the 12 months prior to index (figure 1). Experiencing exacerbations prior to index was associated with greater mean age (56 versus 48 years), female sex (67\% versus 62\%), higher blood eosinophil count $\left(0.40\right.$ versus $0.31 \times 10^{3}$ cells $\left.\mu \mathrm{L}^{-1}\right)$, higher neutrophil count $\left(6.1\right.$ versus $\left.5.1 \mathrm{cells} \cdot \mathrm{mm}^{-3}\right)$ and lower lung function compared with patients with no exacerbations. In addition, patients with exacerbations had a greater use of asthma medications than patients without exacerbations prior to the index date, although $21 \%$ of the patients with two or more exacerbations had no recorded collection of ICSs at index (table 1).

\section{Exacerbations history during the 3 years}

Patients with two or more exacerbations at index were much more likely to have had frequent exacerbations also during the following 2 years (figure 2). Of the 1175 patients with frequent exacerbations at baseline, $47 \%$ also had frequent exacerbations in the first year of follow-up (PPV 0.47, 95\% CI 0.44-0.50). Of those who had frequent exacerbations both at baseline and in the first year of follow-up, $63 \%$ had frequent exacerbations also in the second year of follow-up (PPV 0.63, 95\% CI 0.58-0.67). In total, $328(1.8 \%)$ of the patients had frequent exacerbations during 3 consecutive years. A similar pattern, with a low likelihood of having exacerbations also during follow-up, was observed for the patients who did not have any exacerbations prior to index (figure 2). Of the 15330 patients without exacerbations at baseline, $89 \%$ did not have any exacerbations in the first year of follow-up (NPV 0.89, 95\% CI 0.88-0.89); of those without exacerbation both at baseline and in the first year of follow-up, $91 \%$ did not have any exacerbations in the second year of follow-up (NPV 0.91, 95\% CI 0.90-0.91).

\section{Frequent exacerbations versus no exacerbations}

There was an increase in the percentage of patients collecting an asthma medication during follow-up, both in the group with frequent exacerbations and in the group without exacerbations compared with index (table 2). The use of LTRAs and LABAs increased more in the group with frequent exacerbations compared with those without exacerbations, but no other significant difference in medication change was found between the two groups (table 2). During follow-up, ICS in fixed combinations or as monotherapy

TABLE 1 Baseline patient characteristics of the study population, grouped by the number of exacerbations during the 12 months prior to the index date

\begin{tabular}{|c|c|c|c|c|}
\hline & 0 & 1 & $\geqslant 2$ & $p$-value ${ }^{\#}$ \\
\hline Age & $48.3 \pm 19.3$ & $51.4 \pm 18.5$ & $55.6 \pm 17.9$ & $<0.001$ \\
\hline Female & $9470(61.8)$ & $1503(67.7)$ & $792(67.4)$ & $<0.001$ \\
\hline Neutrophils cells $\cdot \mathrm{mm}^{-3}$ & $5.1 \pm 2.7(n=1407)$ & $5.6 \pm 2.8(n=370)$ & $6.1 \pm 3.0(n=291)$ & $<0.001$ \\
\hline FEV $1 \%$ pred & $85.1 \pm 20.6(n=1176)$ & $81.7 \pm 23.3(n=272)$ & $70.8 \pm 26.0(n=167)$ & $<0.001$ \\
\hline FVC \% pred & $95.9 \pm 18.6(n=1049)$ & $95.1 \pm 19.1(n=224)$ & $87.6 \pm 20.8(n=136)$ & $<0.001$ \\
\hline SABAs & 4642 (30.3) & $1053(47.5)$ & $683(58.1)$ & $<0.001$ \\
\hline LABAs & $1554(10.1)$ & $351(15.8)$ & $244(20.8)$ & $<0.001$ \\
\hline ICSs & $4211(27.5)$ & $814(36.7)$ & $447(38.0)$ & $<0.001$ \\
\hline Fixed ICS/LABA combination & 3709 (24.2) & $827(37.3)$ & $607(51.7)$ & $<0.001$ \\
\hline
\end{tabular}

Data are presented as $\mathrm{n}(\%)$ or mean $\pm \mathrm{SD}$, unless otherwise stated. BMI: body mass index; FEV 1 : forced expiratory volume in $1 \mathrm{~s}$; FVC: forced vital capacity; SABA: short-acting $\beta_{2}$-agonist; LABA: long-acting $\beta_{2}$-agonist; ICS: inhaled corticosteroid; LTRA: leukotriene receptor antagonist.

\#: adjusted for age and sex. 


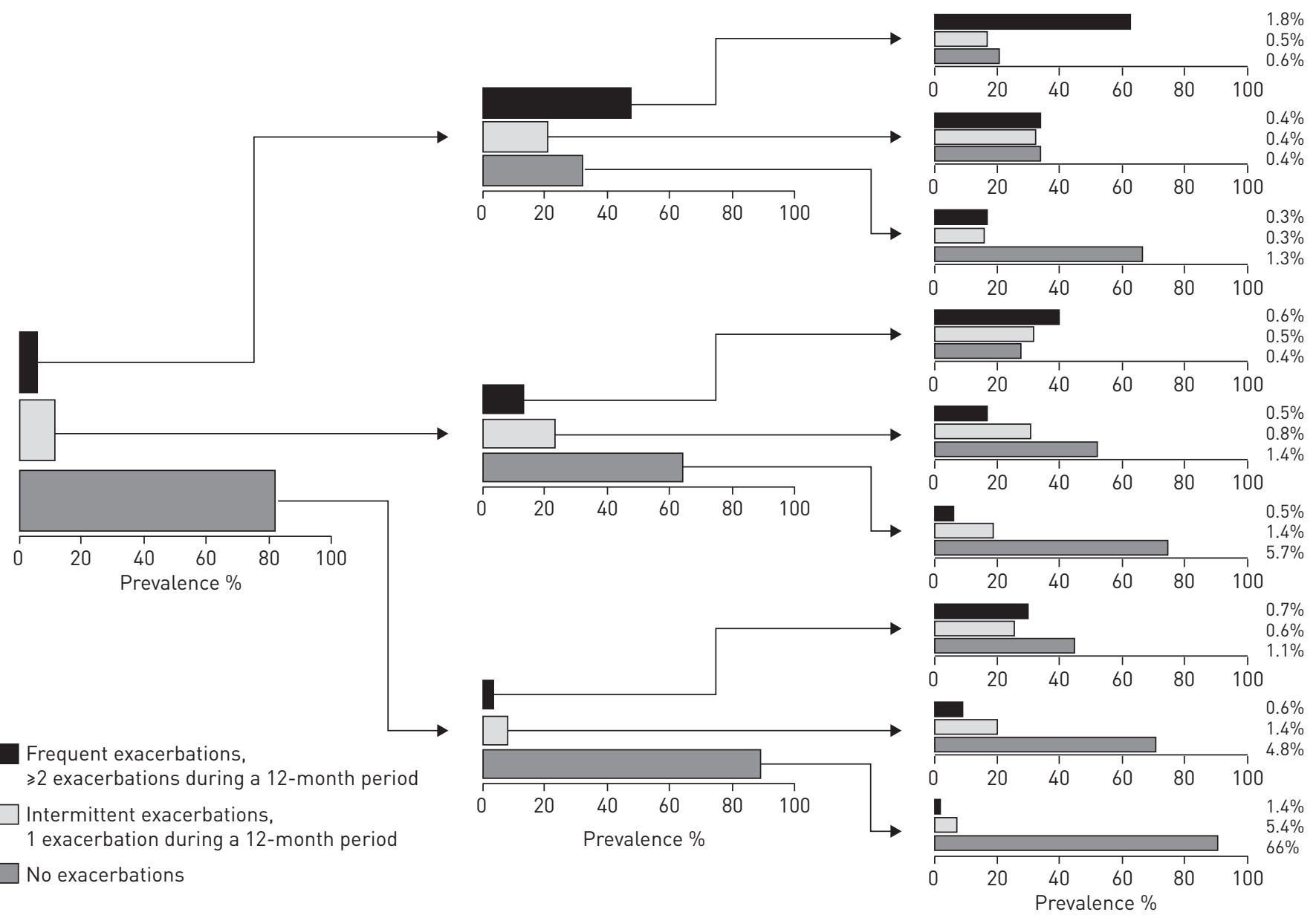

FIGURE 2 Prevalence of exacerbations during each year of the 3-year observation period for patients with frequent, intermittent and no exacerbations during the baseline year.

was collected by significantly more patients in the group with frequent exacerbations (90\%) compared with those without exacerbations (54\%) (table 2).

Healthcare utilisation showed an opposite trend, with a decreased percentage of patients visiting healthcare in both groups during follow-up compared with the 12 months before index (table 3). No significant difference in change in healthcare utilisation was found between the group with frequent exacerbations compared with the group without exacerbations (table 3). However, the percentage of patients with a physician visit due to asthma during the follow-up period, both in primary and secondary care, was greater in the group with frequent exacerbations ( $29 \%$ and $22 \%$, respectively) compared with the group without exacerbations ( $11 \%$ and $2 \%$, respectively) (table 3 ).

The group with repeated frequent exacerbations was older (58 versus 47 years), more often female (67\% versus 61\%), and had increased levels of eosinophils ( 0.46 versus $0.29 \times 10^{3}$ cells $\left.\mu \mathrm{L}^{-1}\right)$, increased levels of neutrophils $\left(6.0\right.$ versus 4.9 cells. $\left.\mathrm{mm}^{-3}\right)$, lower FEV1 \% pred $(66 \%$ versus $87 \%)$ and lower FVC \% pred ( $86 \%$ versus $97 \%$ ) than the group without exacerbations during the study period (table 4 ). In addition, the group with frequent exacerbations had a greater multimorbidity prevalence, also after adjusting for age and sex differences, compared with the group without frequent exacerbations. Comorbidities that differed in this aspect included nasal polyps, chronic sinusitis, chronic bronchitis, COPD, diabetes, hypertension, ischaemic heart disease, stroke, depression and osteoporosis (table 4). Most of the associations reported also remained when excluding patients with concurrent COPD diagnosis, except that there were no significant differences between the groups regarding neutrophils, FVC, stroke and depression (supplementary tables S1-S3). 
TABLE 2 Percentage of patients collecting at least one claim of asthma medication at baseline and during follow-up, grouped by patients with and without frequent exacerbations during the observation period

\begin{tabular}{|c|c|c|c|c|c|c|c|c|c|}
\hline & \multicolumn{3}{|c|}{ No exacerbations ${ }^{\#}$} & \multirow[t]{2}{*}{ p-value } & \multicolumn{3}{|c|}{ Frequent exacerbations" } & \multirow[t]{2}{*}{ p-value } & \multirow{2}{*}{$\begin{array}{c}\text { Groupxtime } \\
\text { interaction } \\
\text { p-value }\end{array}$} \\
\hline & Baseline & Follow-up & $\begin{array}{c}\text { Difference }^{+} \\
(95 \% \mathrm{CI})\end{array}$ & & Baseline & Follow-up & $\begin{array}{l}\text { Difference }^{+} \\
(95 \% \mathrm{CI})\end{array}$ & & \\
\hline LABAs & 9.1 & 10.0 & $0.95(0.48-1.40)$ & $<0.001$ & 20.4 & 25.3 & $4.88(0.95-8.01)$ & 0.015 & 0.045 \\
\hline ICSs & 26.9 & 30.9 & $3.95(3.18-4.72)$ & $<0.001$ & 38.1 & 38.7 & $0.61(-4.32-5.48)$ & 0.90 & 0.15 \\
\hline $\begin{array}{l}\text { Fixed ICS/LABA } \\
\text { combination }\end{array}$ & 21.8 & 25.1 & $3.32(2.71-3.91)$ & $<0.001$ & 54.9 & 61.0 & $6.10(1.55-9.92)$ & 0.008 & 0.29 \\
\hline LTRAs & 3.7 & 4.1 & $0.35(0.04-0.65)$ & 0.024 & 23.5 & 29.9 & $6.40(2.21-9.71)$ & 0.003 & $<0.001$ \\
\hline $\begin{array}{l}\text { Long-acting } \\
\text { anticholinergics }\end{array}$ & 2.8 & 3.7 & $0.91(0.66-1.14)$ & $<0.001$ & 21.0 & 25.6 & $4.57(1.02-7.21)$ & 0.012 & 0.25 \\
\hline
\end{tabular}

Data are presented as $\%$, unless otherwise stated. SABA: short-acting $\beta_{2}$-agonist; LABA: long-acting $\beta_{2}$-agonist; ICS: inhaled corticosteroid; LTRA: leukotriene receptor antagonist. ${ }^{\#}: \mathrm{n}=12036 ;{ }^{\text {ๆ: }} \mathrm{n}=328 ;{ }^{+}$: adjusted for age and sex.

\begin{abstract}
Discussion
The main findings of the present observational study were that an exacerbation-prone asthma phenotype could be identified in a Swedish primary care setting, corresponding to $\sim 2 \%$ of the primary care asthma population, and that the healthcare system seems to be inadequately equipped to adjust the treatment and management in this group of patients with severe asthma. Patients with frequent exacerbations were somewhat older, more often female and were more likely to have multimorbidity than those without exacerbations. The group with frequent exacerbations also had lower lung function and greater blood eosinophil and neutrophil counts than those without exacerbations.

This study indicates the existence of an exacerbations-prone asthma phenotype. This is in accordance with what has been found in one previous study [13] and in line with what has been previously reported for COPD [12]. This group with frequent exacerbations constitutes a minority of the asthma patients managed in primary care, but as asthma is a common disease, these patients may still have a large impact on the costs of asthma management for both healthcare and society [10].

The clinically most important finding in this study is that the healthcare system does not seem to be able to either identify or adjust the level of management in asthma patients with frequent exacerbations. It would be expected that the pharmacological treatment and the frequency of follow-up visits would increase in asthma patients who continue to have frequent exacerbations over time. This was, however, not the case in the present study. There was a slight increase in pharmacological treatment, but this increase was at the same
\end{abstract}

TABLE 3 Healthcare utilisation at baseline and during follow-up, grouped by patients that have frequent exacerbations and those without exacerbations

\begin{tabular}{|c|c|c|c|c|c|c|c|}
\hline \multicolumn{3}{|c|}{ No exacerbations ${ }^{\#}$} & \multirow[t]{2}{*}{ p-value } & \multicolumn{3}{|c|}{ Frequent exacerbations $s^{\pi}$} & \multirow{2}{*}{$\begin{array}{c}\text { p-value Groupxtime } \\
\text { interaction } \\
\text { p-value }\end{array}$} \\
\hline Baseline & Follow-up & $\begin{array}{c}\text { Difference }^{+} \\
(95 \% \text { CI) }\end{array}$ & & Baseline & Follow-up & $\begin{array}{c}\text { Difference }^{+} \\
(95 \% \mathrm{CI})\end{array}$ & \\
\hline
\end{tabular}

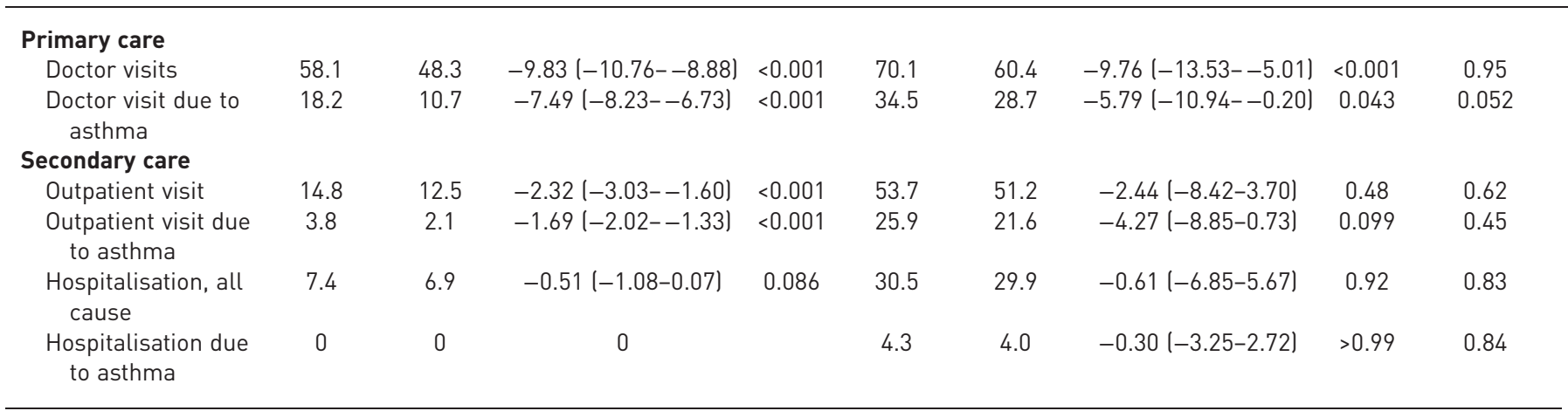

Data are presented as $\%$, unless otherwise stated. ${ }^{\#}: n=12036 ;{ }^{\Uparrow}: n=328 ;{ }^{+}$: adjusted for age and sex. 
TABLE 4 Characteristics of patients without any exacerbations compared with those with frequent exacerbations every year during the observational period

\begin{tabular}{|c|c|c|c|}
\hline & No exacerbations & Frequent exacerbations & p-value $\#$ \\
\hline Patients & 12036 & 328 & \\
\hline Age & $46.9 \pm 18.9$ & $58.0 \pm 16.5$ & $<0.001$ \\
\hline Neutrophils cells $\cdot \mathrm{mm}^{-3}$ & $4.9 \pm 2.5(n=979)$ & $6.0 \pm 2.6(n=84)$ & $<0.001$ \\
\hline Eosinophils $\times 10^{3}$ cells $\mu \mathrm{L}^{-1}$ & $0.29 \pm 0.33(n=1640)$ & $0.46 \pm 0.75(n=109)$ & $<0.001$ \\
\hline BMI & $27.6 \pm 6.0(n=6239)$ & $26.5 \pm 5.2(n=186)$ & 0.017 \\
\hline Rhinitis/sinusitis & $2527(21.0)$ & $84(25.6)$ & 0.048 \\
\hline Nonallergic rhinitis & $530(4.4)$ & $19(5.8)$ & 0.248 \\
\hline Allergic rhinitis & $1944(16.2)$ & 55 (16.8) & 0.766 \\
\hline Chronic rhinitis & $317(2.6)$ & $21(6.4)$ & $<0.001$ \\
\hline Chronic sinusitis & $110(0.9)$ & $10(3.0)$ & 0.002 \\
\hline Nasal polyps & $275(2.3)$ & $26(7.9)$ & $<0.001$ \\
\hline Ischaemic heart disease & 709 (5.9) & $53(16.2)$ & $<0.001$ \\
\hline Cerebrovascular diseases & $301(2.5)$ & $16(4.9)$ & 0.001 \\
\hline Anxiety & $1174(9.8)$ & $38(11.6)$ & 0.283 \\
\hline Depression & $1734(14.4)$ & $62(18.9)$ & 0.028 \\
\hline Osteoporosis & $202(1.7)$ & $19(5.8)$ & $<0.001$ \\
\hline Inflammatory bowel disease & $322(2.7)$ & $14(4.3)$ & 0.105 \\
\hline
\end{tabular}

Data are presented as $n$, mean \pm SD or $n(\%)$, unless otherwise stated. BMI: body mass index; FEV1: forced expiratory volume in $1 \mathrm{~s}$; FVC: forced vital capacity; COPD: chronic obstructive pulmonary disease. " : adjusted for age and sex.

level as observed for the group with no exacerbations during the 3-year observation period. Concomitantly, there was a decrease in both primary and secondary care physician visits in both groups during the same time. According to international guidelines, patients with severe asthma should be managed by pulmonary specialists [1]. In this study, only one-third of the patients with frequent exacerbations were seen by a secondary care specialist, indicating that the healthcare system has failed to identify and adjust the management of this patient population. We also found that $10 \%$ of those with frequent exacerbations had not collected ICSs, which indicates that some of the patients in this group are undermedicated.

The finding that the group with frequent exacerbations was older is in accordance with several other studies, showing lower HRQoL and reduced asthma control in older asthma patients [7, 33]. In our study, females were more likely to have frequent exacerbations, which is in keeping with studies showing a lower HRQoL in females with asthma than in males with asthma [34] and that female sex is related to having uncontrolled asthma [35].

In the present study, the group with frequent exacerbations had lower FEV1 \% pred and FVC \% pred compared with those without exacerbations. These results are in agreement with those of BAI et al. [11], who found that having frequent exacerbations was related to a more rapid decline of lung function in asthma patients. In addition, having frequent exacerbations was related to greater counts of both eosinophils and neutrophils. The association between exacerbations and eosinophil counts is well known [13-15], and the introduction of anti-IL-5 treatment has shown that this is a relevant target for reducing exacerbations in some asthma patients [17]. An association between greater neutrophil count and increased risk for exacerbations has also been shown in previous studies $[14,36]$, and it is possible that therapy that will target the neutrophilic inflammation may be relevant to reduce exacerbations in asthma in the future.

Several comorbidities were related to frequent exacerbations in the present study. The associations between frequent exacerbations and upper airway diseases are in accordance with previous studies, showing an association between chronic rhinosinusitis and low asthma-related quality of life [7], as well as studies showing that treating rhinitis with nasal corticosteroids may reduce exacerbations in asthma [37]. In COPD, having chronic bronchitis is related to exacerbations [38] and chronic productive cough has been related to frequent exacerbations in asthma [39]. In the present study, the group with frequent exacerbations was more likely to have a concomitant diagnosis of COPD. This is in accordance with several other studies reporting 
that patients with asthma-COPD overlap are more likely to have exacerbations than those with only one of the diseases $[22,23]$. The term asthma-COPD overlap syndrome ("ACOS") was introduced indicating that this is a group of patients that need special attention [40]. The term has now been changed to asthmaCOPD overlap ("ACO") in order to emphasise that having both asthma and COPD is not a distinct disease [41]. The group with frequent exacerbations also had a higher prevalence of depression, cardiovascular disease and inflammatory bowel disease. In COPD, an association between health status and the number of comorbidities has been reported [42], but less is known of the role of comorbidities in asthma. One likely explanation for the association between multimorbidity and exacerbations in asthma may be that triggers, e.g. viral infections, are more likely to cause an exacerbation in asthmatic individuals whose health is already decreased by other diseases. The association between having frequent exacerbations and multimorbidity remained after excluding patients with concurrent COPD.

The strength of this study is that it is a large observational study with no selection bias, linking electronic primary healthcare data to mandatory national health registers with high coverage and quality. It can therefore be expected that the study results present a real-life picture of the management of asthma patients in a Swedish primary care setting. However, this is a retrospective, observational registry study, a design that has its limitations. Comprehensive phenotypic and personal characteristics, such as lung function measurements and biomarkers, were only available for a limited number of patients, and data on allergic sensitisation and smoking were lacking. The exacerbations were identified by short courses of OCSs, as manually verified. Still, it cannot be completely ruled out that some use of short courses of OCSs was indicated by chronic diseases other than asthma.

In conclusion, we found that there is a group of asthma patients, also in a Swedish primary care setting, who have frequent exacerbations, characterised by greater age, female predominance, high eosinophil and neutrophil counts, and high level of comorbidities. In addition, the present study indicates that the healthcare system lacks the efficiency to adjust the level of treatment and management for this severe asthma population. With the availability of new treatment options targeting severe asthma, these patients would likely benefit from being identified and evaluated in order to ensure reduced frequency of exacerbations and increased HRQoL.

Conflict of interest: C. Janson reports payment for lectures, including service on speaker's bureaus from AstraZeneca, Teva and Novartis, outside the submitted work. K. Lisspers reports personal fees for membership of the steering committee, during the conduct of this work; and payment for lectures, including service on speaker's bureaus from AstraZeneca, Novartis and Teva, and payment for manuscript preparation from Meda, outside the submitted work. B. Ställberg reports personal fees from AstraZeneca for participation in the study steering committee, during the conduct of this work; and personal fees for advisory board work from AstraZeneca, Boehringer Ingelheim, Novartis and Meda, payment for lectures, including service on speaker's bureaus from AstraZeneca, Novartis, Meda and Teva, and payment for development of educational presentations from AstraZeneca and Teva, outside the submitted work. M. Thuresson reports fees for statistical consultations, both during the conduct of this work and outside the submitted work. G. Telg is a full-time employee of AstraZeneca, the study sponsor. K. Larsson reports personal fees for advisory board work from AstraZeneca, Boehringer Ingelheim, Novartis and Chiesi, and payment for lectures, including service on speaker's bureaus from AstraZeneca, Boehringer Ingelheim, Novartis, Chiesi, Orion and Takeda, outside the submitted work.

Support statement: The study was sponsored by AstraZeneca. Funding information for this article has been deposited with the Crossref Funder Registry.

\section{References}

1 Global Initiative for Asthma. Global Strategy for Asthma Management and Prevention. 2016. Available from: http://ginasthma.org/

2 Cazzoletti L, Marcon A, Janson C, et al. Asthma control in Europe: a real-world evaluation based on an international population-based study. J Allergy Clin Immunol 2007; 120: 1360-1367.

3 Stallberg B, Lisspers K, Hasselgren M, et al. Asthma control in primary care in Sweden: a comparison between 2001 and 2005. Prim Care Respir J 2009; 18: 279-286.

4 Price DB, Baker CL, Zou KH, et al. Real-world characterization and differentiation of the Global Initiative for Chronic Obstructive Lung Disease strategy classification. Int J Chron Obstruct Pulmon Dis 2014; 9: 551-561.

5 Rabe KF, Vermeire PA, Soriano JB, et al. Clinical management of asthma in 1999: the Asthma Insights and Reality in Europe (AIRE) study. Eur Respir J 2000; 16: 802-807.

6 Siroux V, Boudier A, Anto JM, et al. Quality-of-life and asthma-severity in general population asthmatics: results of the ECRHS II study. Allergy 2008; 63: 547-554.

7 Ek A, Middelveld R, Bertilsson H, et al. Chronic rhinosinusitis in asthma is a negative predictor of quality of life: results from the Swedish GA²LEN Survey. Allergy 2013; 68: 1314-1321.

8 Accordini S, Corsico A, Cerveri I, et al. The socio-economic burden of asthma is substantial in Europe. Allergy 2007; 63: 116-124

9 Accordini S, Corsico AG, Braggion $\mathrm{M}$, et al. The cost of persistent asthma in Europe: an international population-based study in adults. Int Arch Allergy Immunol 2013; 160: 93-101. 
10 Ivanova JI, Bergman R, Birnbaum HG, et al. Effect of asthma exacerbations on health care costs among asthmatic patients with moderate and severe persistent asthma. J Allergy Clin Immunol 2012; 129: 1229-1235.

11 Bai TR, Vonk JM, Postma DS, et al. Severe exacerbations predict excess lung function decline in asthma. Eur Respir J 2007; 30: 452-456.

12 Hurst JR, Vestbo J, Anzueto A, et al. Susceptibility to exacerbation in chronic obstructive pulmonary disease. N Engl J Med 2010; 363: 1128-1138.

13 Denlinger LC, Phillips BR, Ramratnam S, et al. Inflammatory and co-morbid features of patients with severe asthma and frequent exacerbations. Am J Respir Crit Care Med 2016; 193: 634-641.

14 Westerhof GA, de Groot JC, Amelink M, et al. Predictors of frequent exacerbations in (ex)smoking and never smoking adults with severe asthma. Respir Med 2016; 118: 122-127.

15 Janson C, Herala M. Blood eosinophil count as risk factor for relapse in acute asthma. Respir Med 1992; 86: 101-104.

16 Bleecker ER, FitzGerald JM, Chanez P, et al. Efficacy and safety of benralizumab for patients with severe asthma uncontrolled with high-dosage inhaled corticosteroids and long-acting $\beta_{2}$-agonists (SIROCCO): a randomised, multicentre, placebo-controlled phase 3 trial. Lancet 2016; 388: 2115-2127.

17 Pavord ID, Korn S, Howarth P, et al. Mepolizumab for severe eosinophilic asthma (DREAM): a multicentre, double-blind, placebo-controlled trial. Lancet 2012; 380: 651-659.

18 FitzGerald JM, Bleecker ER, Nair P, et al. Benralizumab, an anti-interleukin-5 receptor $\alpha$ monoclonal antibody, as add-on treatment for patients with severe, uncontrolled, eosinophilic asthma (CALIMA): a randomised, double-blind, placebo-controlled phase 3 trial. Lancet 2016; 388: 2128-2141.

19 Barnett K, Mercer SW, Norbury M, et al. Epidemiology of multimorbidity and implications for health care, research, and medical education: a cross-sectional study. Lancet 2012; 380: 37-43.

20 Leynaert B, Bousquet J, Neukirch C, et al. Perennial rhinitis: an independent risk factor for asthma in nonatopic subjects: results from the European Community Respiratory Health Survey. J Allergy Clin Immunol 1999; 104: 301-304.

21 Passalacqua G, Ciprandi G, Canonica GW. United airways disease: therapeutic aspects. Thorax 2000; 55: Suppl. 2, S26-S27.

22 de Marco R, Marcon A, Rossi A, et al. Asthma, COPD and overlap syndrome: a longitudinal study in young European adults. Eur Respir J 2015; 46: 671-679.

23 Milanese M, Di Marco F, Corsico AG, et al. Asthma control in elderly asthmatics. An Italian observational study. Respir Med 2014; 108: 1091-1099.

24 Cerveri I, Cazzoletti L, Corsico AG, et al. The impact of cigarette smoking on asthma: a population-based international cohort study. Int Arch Allergy Immunol 2012; 158: 175-183.

25 Chung WS, Lin CL, Chen YF, et al. Increased stroke risk among adult asthmatic patients. Eur J Clin Invest 2014; 44: $1025-1033$

26 Jerning C, Martinander E, Bjerg A, et al. Asthma and physical activity - a population based study results from the Swedish GA²LEN survey. Respir Med 2013; 107: 1651-1658.

27 Stallberg B, Janson C, Johansson G, et al. Management, morbidity and mortality of COPD during an 11-year period: an observational retrospective epidemiological register study in Sweden (PATHOS). Prim Care Respir J 2014; 23: 38-45.

28 Janson C, Larsson K, Lisspers $\mathrm{KH}$, et al. Pneumonia and pneumonia related mortality in patients with COPD treated with fixed combinations of inhaled corticosteroid and long acting beta ${ }_{2}$ agonist: observational matched cohort study (PATHOS). BMJ 2013; 346: f3306.

29 Martinell M, Stalhammar J, Hallqvist J. Automated data extraction - a feasible way to construct patient registers of primary care utilization. Ups J Med Sci 2012; 117: 52-56.

30 Franzen S, Janson C, Larsson K, et al. Evaluation of the use of Swedish integrated electronic health records and register health care data as support clinical trials in severe asthma: the PACEHR study. Respir Res 2016; 17: 152.

31 Lisspers K, Stallberg B, Hasselgren M, et al. Organisation of asthma care in primary health care in Mid-Sweden. Prim Care Respir J 2005; 14: 147-153.

32 Thorn J, Norrhall M, Larsson R, et al. Management of chronic obstructive pulmonary disease (COPD) in primary care: a questionnaire survey in western Sweden. Prim Care Respir J 2008; 17: 26-31.

33 Kampe M, Lisspers K, Stallberg B, et al. Determinants of uncontrolled asthma in a Swedish asthma population: cross-sectional observational study. Eur Clin Respir J 2014; 1: 24109.

34 Lisspers K, Stallberg B, Janson C, et al. Sex-differences in quality of life and asthma control in Swedish asthma patients. J Asthma 2013; 50: 1090-1095.

35 Siroux V, Boudier A, Bousquet J, et al. Phenotypic determinants of uncontrolled asthma. J Allergy Clin Immunol 2009; 124: 681-687.

36 Nadif R, Siroux V, Boudier A, et al. Blood granulocyte patterns as predictors of asthma phenotypes in adults from the EGEA study. Eur Respir J 2016; 48: 1040-1051.

37 Adams RJ, Fuhlbrigge AL, Finkelstein JA, et al. Intranasal steroids and the risk of emergency department visits for asthma. J Allergy Clin Immunol 2002; 109: 636-642.

38 Sundh J, Johansson G, Larsson K, et al. The phenotype of concurrent chronic bronchitis and frequent exacerbations in patients with severe COPD attending Swedish secondary care units. Int J Chron Obstruct Pulmon Dis 2015; 10: 2327-2334.

39 Siroux V, Basagana X, Boudier A, et al. Identifying adult asthma phenotypes using a clustering approach. Eur Respir J 2011; 38: 310-317.

40 Global Initiative for Asthma. Global Strategy for Asthma Management and Prevention. 2014. Available from: http://ginasthma.org/

41 Global Initiative for Asthma. Global Strategy for Asthma Management and Prevention. 2017. Available from: http://ginasthma.org/

42 Sundh J, Johansson G, Larsson K, et al. Comorbidity and health-related quality of life in patients with severe chronic obstructive pulmonary disease attending Swedish secondary care units. Int J Chron Obstruct Pulmon Dis 2015; 10: 173-183. 